\title{
Effects of Biaxial Loading on the High Temperature Behaviour of Concrete
}

\author{
K. KORDINA and C. EHM
}

Institut für Baustoffe, Massivbau und Brandschutz

Technische Universität Braunschweig

Beethovenstrasse 52, D-3300 Braunschweig, FRG

\section{U. SCHNEIDER}

Fachgebiet Baustoffkunde

Universität Gesamthochschule Kassel, FRG

\begin{abstract}
Biaxial compression tests with ordinary concrete have been carried out under steady state and transient temperature conditions. The test results show that even small load levels in a second axis alter the mechanical properties of concrete significantly. The stress-strain relationships. show a significant dependence on the temperature level and the stress ratio. The strength under biaxial compressive stress is higher than the strength under uniaxial compression. The volumetric strains increase with increasing stress ratios and increasing temperatures. The failure temperature of specimens being biaxially loaded is higher than the one of specimens that are uniaxially loaded. The modes of failure indicate that the tensile deformation is vital for the failure mechanism of concrete.
\end{abstract}

\section{INTRODUCTION}

During fires in buildings, concrete structures are exposed to mechanical and thermal stresses. With respect to mechanical stress states, there are uniaxial stresses, for example in centrically loaded columns, biaxial stresses, for example in beams, panels, slabs and shells and triaxial stresses. Regarding the temperature exposure, there are the ambient temperature, increasing and high temperatures when the fire is burning and decreasing temperatures, when the burning has gone out.

This paper deals with the behaviour of concrete under biaxial stress states and steady or transient high temperatures.

Up to now, only: little is known about the strength and the deformation behaviour of concrete subjected to biaxial stresses at elevated temperatures. Our current knowledge about high temperature behaviour is mainly based on uniaxial experiments, see for example /1/. The knowledge about concrete behaviour under biaxial loading conditions is based on experiments being performed at ambient temperature as it is presented in, for instance, $/ 2 /$.

In the following, at first the test equipment which was especially developed for these investigations will be presented and then some results concerning the strength and deformation behaviour of concrete under complex loading and temperature conditions will be 
discussed. The fracture behaviour under biaxial high temperature stress was already clearly presented in $/ 3 /$.

\section{EXPERIMENTAL EQUIPMENT}

\section{Loading Equipment}

The loading frame of the test equipment (fig. 1) is designed as a welded steel construction of high stiffness. The mechanical loading of the specimens is achieved by four stress rate or strain rate controlled hydraulic cylinders each with a maximum force of 1000 $k N$. The heat resistant pressure pistons are cooled by water.

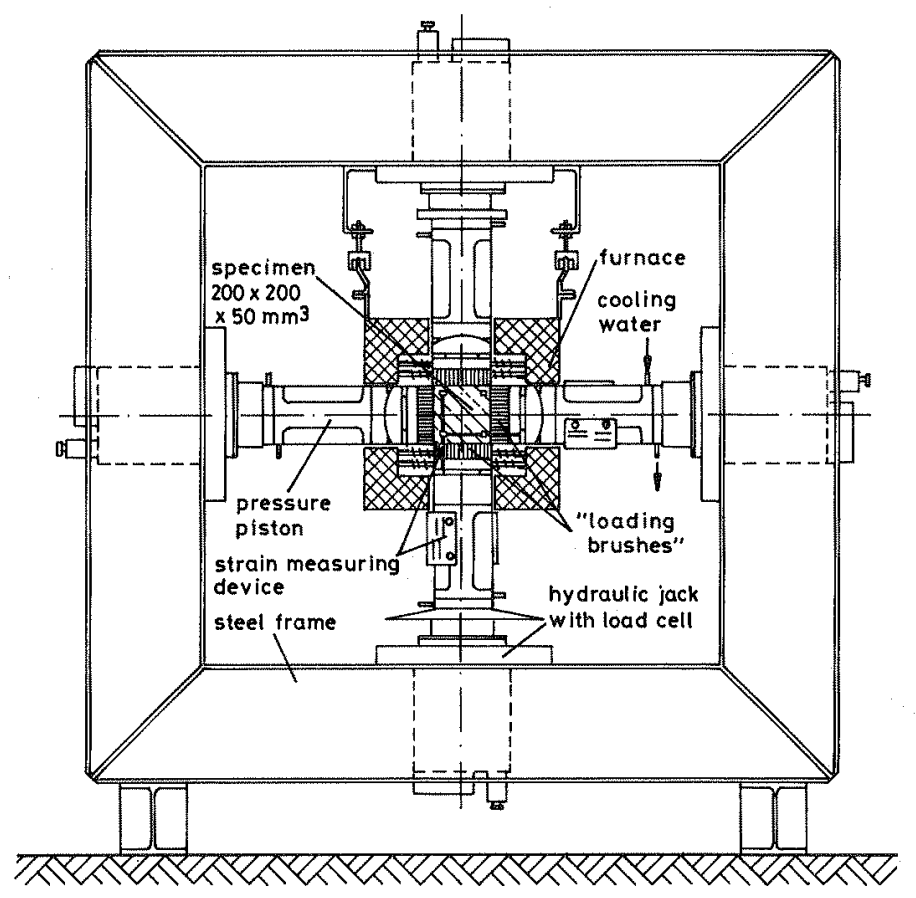

Fig. 1 Test rig for biaxial high temperature concrete tests

\section{Shape of Specimens and Load Application}

Investigations of the mechanical properties of concrete under biaxial stress states at ambient temperature have shown that the uniform, two dimensional state of stress can best be achieved by the use of a disc-shaped specimen. This type of a specimen was chosen for the given investigations at high temperatures, too. The size of the specimens which are sawed out of cubes, results from concrete technological and experimental requirements. The optimum specimen size we obtained after different pre-investigations is $200 \mathrm{x} 200 \mathrm{x}$ $50 \mathrm{~mm}^{3}$. 
Particular problems in biaxial testing arise at high temperatures due to the load application onto the specimens. Generally a nearly unrestrained load application is required and the test equipment must provide a defined and homogeneous state of stress in the specimens. In order to minimize the restraining due to the friction between loading platens and the specimens' surfaces so-called "loading-brushes" were constructed as proposed by Hilsdorf $/ 4 /$. Each load application steel platen is divided into 190 parallel rods having a distance of about $0,1 \mathrm{~mm}$ from each other. These rods follow the deformations of the loaded specimens' surfaces and therefore cause a considerable reduction of the transverse strain inhibition.

By comparing the uniaxial and biaxial high temperature compressive strength data determined with "Ioading-brushes" and with rigid steel platens, the reduction of the strain inhibition by using "Ioading-brushes" was proved. The strengths determined with brushes were more than 20 per cent lower than the strengths determined with rigid platens.

By additional experiments, it could clearly be proved that a defined uniaxial state of stress is achieved in the test specimens by using "loading-brushes". The measured compressive strength is the real uniaxial compressive strength.

\section{Load Control}

The control units of the test equipment fulfill the following important requirements:

- different types of loading and different stress paths can be realized;

- the central point of the specimen is in the centre of the loading during the whole test.

The last point especially apply to experimental conductions under biaxial high temperature conditions. For that the controls are put in the way that the deformations appearing during the heating and the loading of the specimen are synchronously accounted for by the loading units.

\section{Load Measurements}

In order to measure the forces in the specimens, four load cells are at disposal constructed between cylinders and the specimen. The application of two load cells per axis gives the possibility to control the correct installation of the specimens and to discover errors in the system.

\section{Deformation Measurements}

The deformation of the concrete specimens in the three axes are measured directly by means of a specially developed high temperature - deformation measuring device (fig. 2). With this device, the strains are transferred by transmitters out of the hot furnace regions. Inductive displacement transducers are installed in the region of ambient temperatures. The deformation measuring system for the determination of the deformations in the loaded axes is 
designed according to the principle of a dilatometer, that means thermal strains of the transmitters are compensated by a special geometric arrangement. With the measurements of the strains in the unstressed axis, the system is conducted according to a lateral extensometer. The thermal strains of the transmitters separately determined by calibration tests must be taken into consideration.

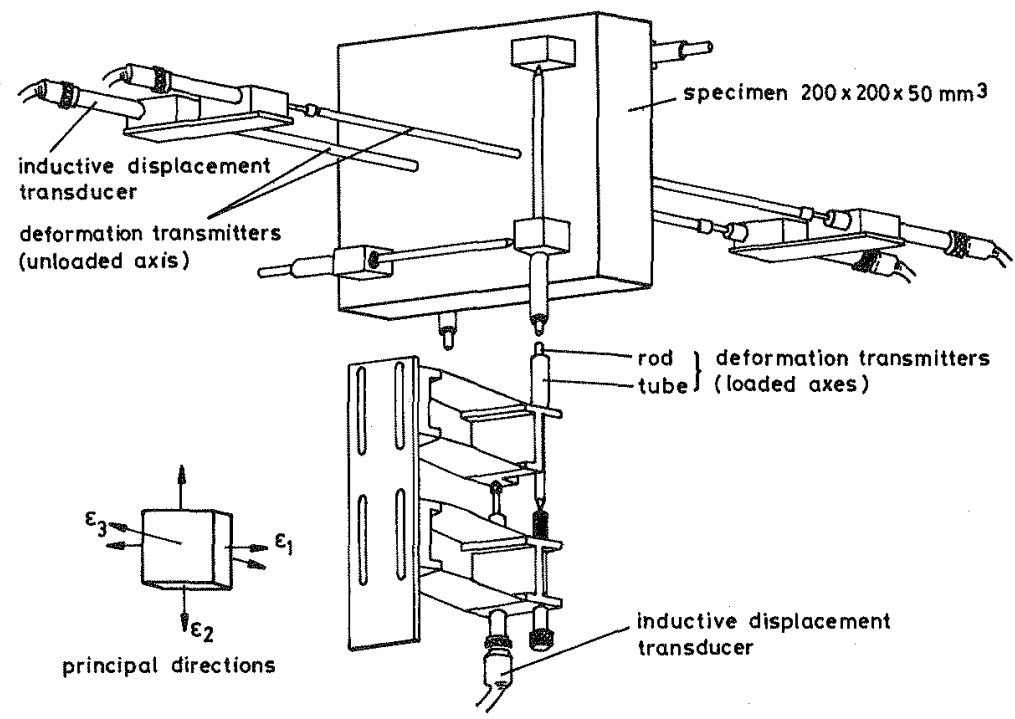

Fig. 2 High temperature deformation measuring system

\section{Heating System and Temperature Measurements}

The heating system consists of an electrical furnace and a 3- zonePID programme controler regulating the heating and cooling of the specimens and the realization of prescribed temperature curves.

The temperature of the specimen is measured with $\mathrm{NiCr}-\mathrm{Ni}$ - thermocouples which are applied on the surface of the specimen by means of a heat-resistant glue. A sufficiently long hold time period of 2 hours and a moderate temperature increase of $2 \mathrm{~K} / \mathrm{min}$ guarantee a uniform temperature distribution in the specimen.

A more detailed description of the experimental equipment is given in $/ 3 /$ and $/ 5 /$.

\section{RESULTS}

\section{Compressive Strength}

In the investigations to determine the biaxial compressive strengths at high temperatures all specimens were stored at least six months at $20^{\circ} \mathrm{C} / 65 \% \mathrm{r} . \mathrm{h}$.. The specimens were made of ordinary concrete with a cube strength of $41,0 \mathrm{~N} / \mathrm{mm}^{2}$ after 28 days. The biaxial compressive strengths are presented in figure 3 . They are 


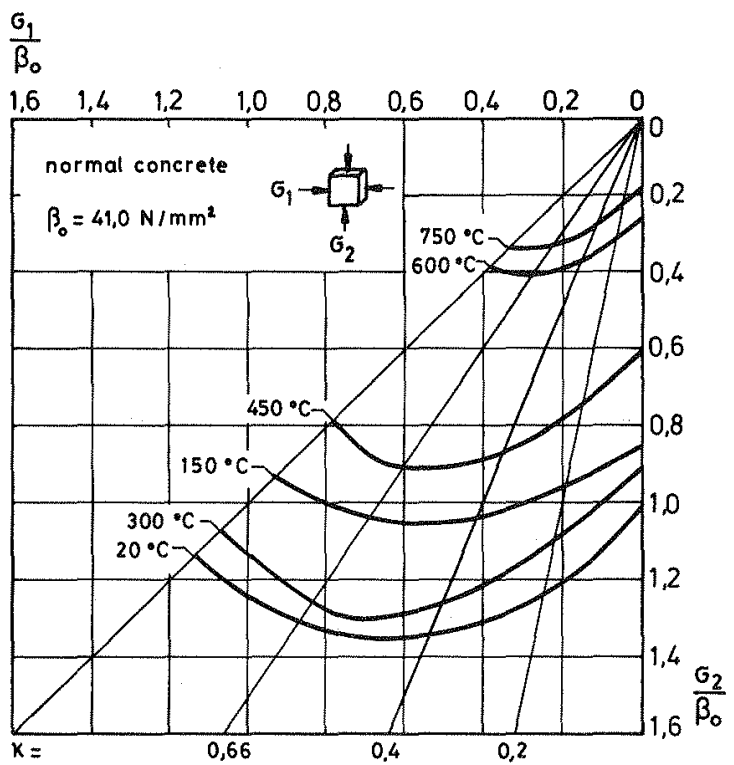

Fig. 3 Biaxial high temperature compressive strength of gravel concrete related to the uniaxial strength at room temperature

related to the uniaxial compressive strength at ambient temperature $B_{0}$ at the time of testing.

For each particular temperature, the strengths were connected with a failure envelope in the plane of principal stresses.

Concerning the biaxial high temperature compressive strength, the following statements can be made:

1. The biaxial compressive strength of concrete is higher than the uniaxial compressive strength. This comprises all temperatures and all stress ratios $k$. The increase of the strength compared to the uniaxial strength is clear even with only small stress levels in the second axis.

2. The biaxial compressive strength increases considerably with increasing stresses in the second axis. The positive effect of the stresses in the second axis obtains its greatest value with a certain stress ratio which depends on the test temperature. A further increase of the stress in the second axis beyond this point consequently decreases the biaxial compressive strength.

3. The relativ increase of the strength under biaxial stress is greater at higher temperatures than at ambient temperature. At ambient temperature, the maximum increase of the strength comes to $20-40$ per cent at a stress ratio of $\sigma_{1}: \sigma_{2}=0,5$. At $750^{\circ} \mathrm{C}$ this value is of the order of 200 per cent at $\sigma_{1}: \sigma_{2}=1,0$.

This means that the maximum of the increase of the strength under biaxial stress shifts with increasing test temperatures to higher stress ratios. This is also valid for concretes with a higher cube 
strength, as shown in $/ 5 /$.

\section{Mechanical strains}

The mechanical strains $\varepsilon_{1}, \varepsilon_{2}$ and $\varepsilon_{3}$ at constant temperatures are presented in the figures 4 and 3 . The deformations depend on the stress level, the stress ratio and the test temperature. The deformations increase with increasing load in all three axes. At high stress levels, they show a nonlinear relation in the direction of the greatest principal stress.

With increasing temperatures, the development of $\sigma-\varepsilon-$ curves indicates a decrease of the compressive strength. The decreasing slope in the origin shows the decrease of the modulus of elasticity at higher temperatures. The ultimate strains for all three axes are shifted to greater values with increasing temperatures. A

particularly great increase of the deformations is observed from $600^{\circ} \mathrm{C}$ onward.

At higher temperatures, the $\sigma-\varepsilon$ - curves are highly non-linear: the concrete changes its brittle behaviour into a soft and plastic

behaviour.

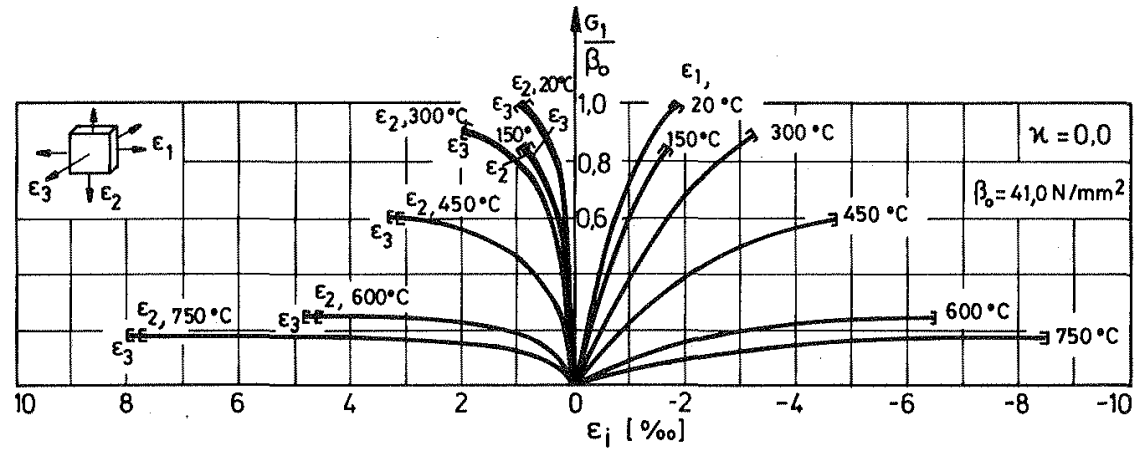

Fig. 4 Stress-strain relations of gravel concrete under uniaxial compressive stresses

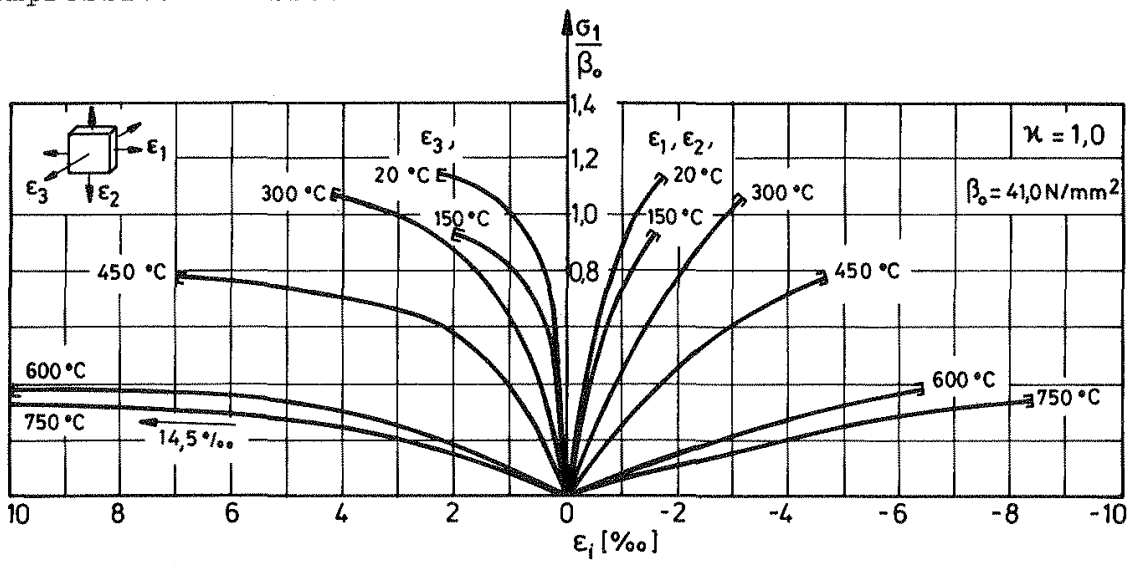

Fig. 5 Stress-strain relations of gravel concrete under symmetrical biaxial compressive stresses 
In the uniaxial case, figure $4, \varepsilon_{2}$ and $\varepsilon_{3}$ are equal because of In the biaxial case with $\sigma_{1}: \sigma_{2}=0,4 \mathrm{e} \cdot \mathrm{g} ., \varepsilon_{2}$ has changed and obtained positive values.

In the symmetrical biaxial case, $\sigma_{1}: \sigma_{2}=1,0$ (figure 5) $\varepsilon_{1}$ and $\varepsilon_{2}$ have the same value.

The strains in the unstressed axis, $\varepsilon_{3}$, reach extremely great values at elevated temperatures and hlgh stress ratios. The maximum values of $\varepsilon_{3}$ appear with the stress ratio $\sigma_{1}: \sigma_{2}=1,0$.

\section{Total Deformations during Heating}

With respect to the case of fire, it is important to investigate the concrete behaviour at transient temperatures. Therefore high temperature transient creep tests were performed.

In such tests, the total deformations of unsealed specimens are measured under practical stress levels and defined non-steady temperature exposures.

Results of the deformation measurements in the uniaxial case for different stress levels are presented in $f^{2} i g u r e$. The elastic deformations at ambient temperatures are neglected in that figure. As a comparison curve, the curve with a zero stress level, i.e. pure thermal expansion is shown in figure 6 , too.

Stress levels of about 70 per cent of the uniaxial strength restrain the thermal extension in the direction of the loaded axis. In this case, only slight extensions can be observed. With continuously increasing temperatures comparatively great

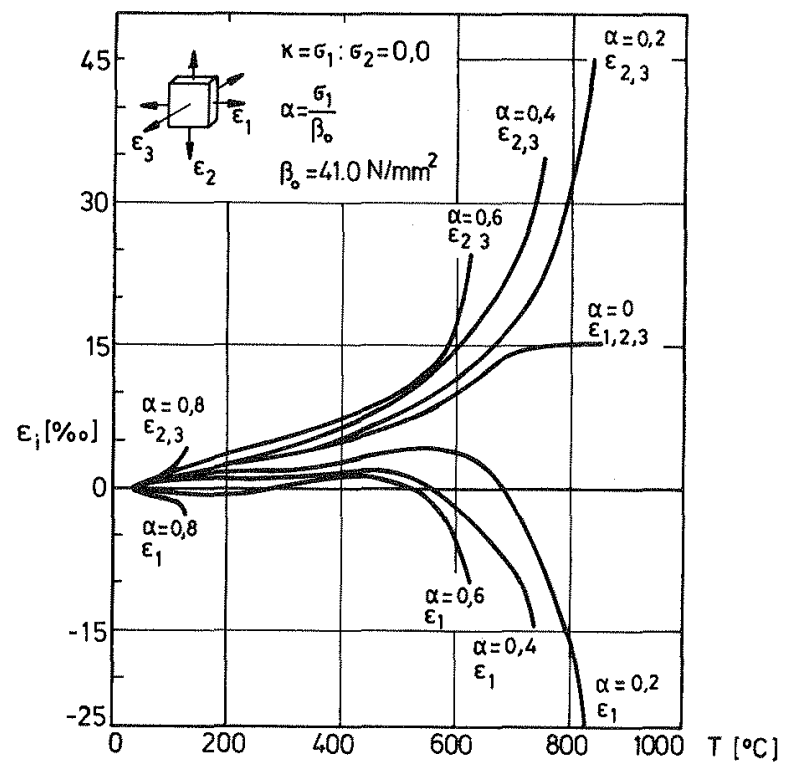

Fig. 6 Total deformations of gravel concrete during uniaxial transient creep tests 


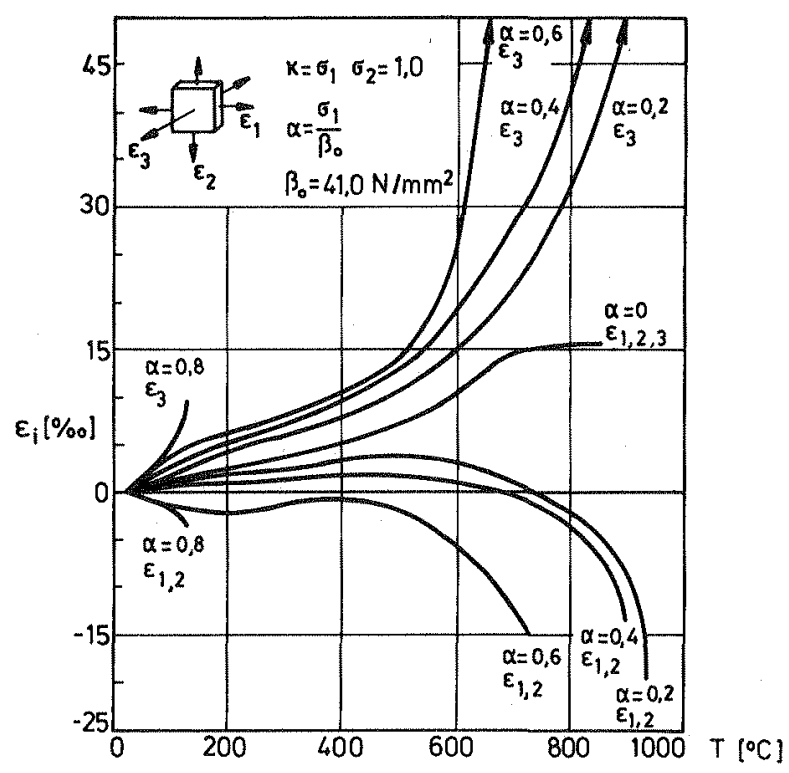

Fig. 7 Total deformations of gravel concrete during biaxial transient creep tests

compressive strains occur until the specimen fails. Stress levels above 70 per cent lead to a failure of the specimen at low temperatures of about $120^{\circ} \mathrm{C}$ to $130^{\circ} \mathrm{C}$.

A fast increase of the lateral strains indicates the failure of the specimens. A symmetrical biaxial stress during heating (fig. 7) leads to extreme lateral strains in the free axis. The compressive strains in the stressed axes are not much greater than in the uniaxial case.

\section{Failure Temperatures}

In figure 8, the failure temperatures are presented. The individual stress ratios serve as a parameter in this graph. Three regions of failure can be distinguished: a stress level of 0 up to 70 per cent of the uniaxial compressive strength leads to failure temperatures above $600^{\circ} \mathrm{C}$. Between 70 and 80 per cent, there is a very sensitive region with regard to the failure temperature. Only slight alterations in the stress level lead to failure temperatures that differ around several hundred centigrade. Stress ratios above 80 per cent consequently lead to failure at temperatures under $130^{\circ} \mathrm{C}$. It has to be considered that in this region the time effect i.e. the duration of the stress exposure plays an important part in addition to the temperature effect.

With increasing stress ratios the failure temperatures increase. According to our tests, the optimum ratio is in the range of $\sigma_{1}$ : $\sigma_{2}=0,4$. The failure temperatures increase significantly in this case. In the region of high stress levels, this increase is of the order of several hundred centigrade. 


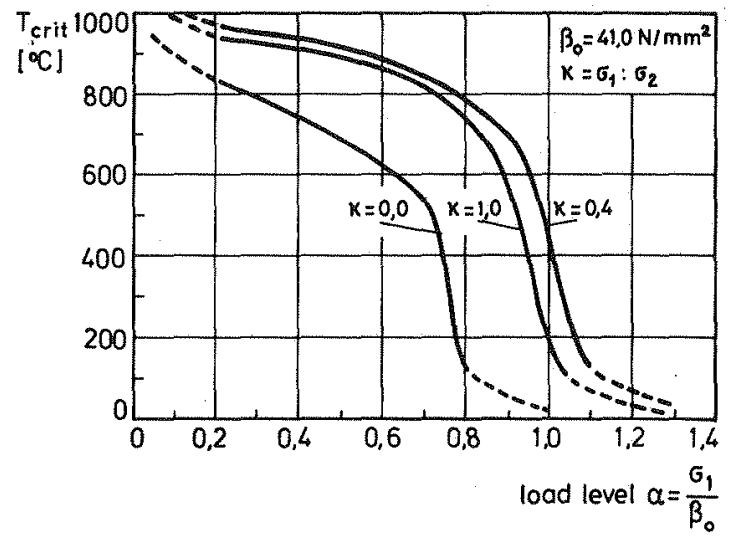

Fig. 8 Failure temperatures of gravel conorete

Restraining Stresses during Heating

Restraining forces arise in concrete specimens under transient temperatures if mechanically or thermally caused extensions are restrained. The time dependent restraining forces of different concrete specimens are show in figure 9. Predried and normal cured specimens are compared.

Up to $120^{\circ} \mathrm{C}$, the restraining forces rise considerably for a normally stored concrete $\left(20^{\circ} \mathrm{C} / 65 \% \mathrm{r} . \mathrm{h}.\right)$. After that a phase of shrinking follows between $120^{\circ} \mathrm{C}$ and $200^{\circ} \mathrm{C}$. During this phase the restraining forces decrease. After passing a minimum at $200^{\circ} \mathrm{C}$, the restraining forces increase again with increasing temperature and reach maximum values at $300^{\circ} \mathrm{C}$ to $350^{\circ} \mathrm{C}$. These values are around 50 to 70 per cent of the failure load at ambient temperature. Finally the restraining forces decrease continuously.

The behaviour of specimens that were predried at $105^{\circ} \mathrm{C}$ is something different. At $200^{\circ} \mathrm{C}$, a distinct stress maximum appears. The restraining forces reach values between 70 and 90 per cent of the failure load at $20^{\circ} \mathrm{C}$.

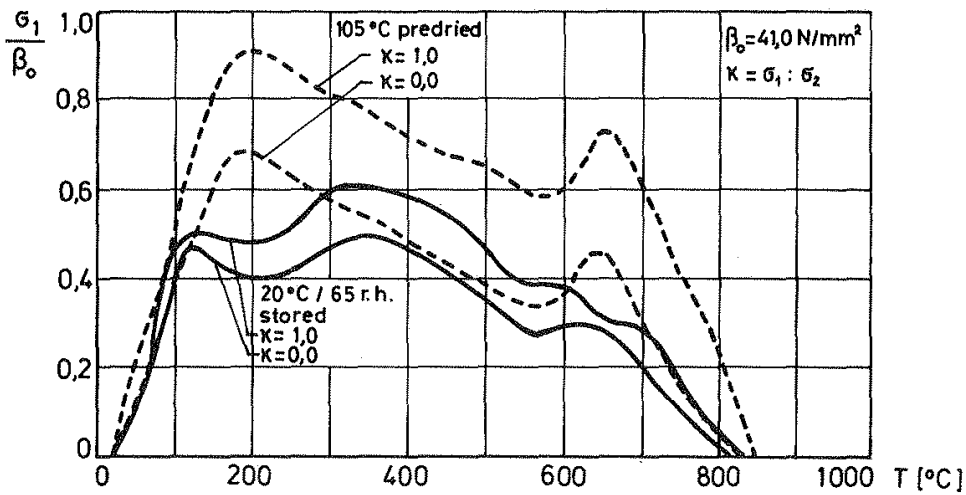

Fig. 9 Restraining stresses of gravel concrete during heating 
Thereafter the restraining forces decrease rapidly. A second maximum appears at $650^{\circ} \mathrm{C}$.

The values of the thermal expansion and the oreep deformations of the concrete have an essential influence on the development of the restraining forces during heating. Vaporisation and dehydration processes are of importance. The development of restraining forces in predried and normally stored specimens in the temperature region of $20^{\circ} \mathrm{C}$ to $200^{\circ} \mathrm{C}$ shows this distinctly. The higher moisture content $\left(20^{\circ} \mathrm{C} / 65 \% \mathrm{r} . \mathrm{h}.\right)$ in the cured specimens favours the creep of concrete so that there are considerably lower restraining forces in comparison with the predried specimens.

The stress ratio influences the quantitative development of the restraining forces, too. The biaxial stresses cause higher restraining forces of the order of 5 to 10 per cent compared to the uniaxial case.

\section{CONCLUSIONS}

Up to now, the experimental results can briefly be summarized as follows:

The biaxial high temperature tests have shown that even small load levels in the second axis alter the mechanical properties of concrete significantly. The strength under biaxial compression is higher than under uniaxial compression. This applies especially to higher temperatures. The strains increase with increasing stress ratios and with increasing temperatures.

The modes of failure indicate that tensile deformations are vital in the failure mechanism of concrete. The increase in strength and stiffness under biaxial compression is supposed to be due to the restraining of thermally induced and load induced microcracking. Studies on crack initiation and development will be performed to establish a theoretical background for the preliminary explanations.

Further experimental investigations are also necessary to proceed in the developing of analytical high temperature material models in order to describe the concrete behaviour as realistically as possible under extreme stresses and temperature conditions.

\section{LITERATURE}

11/ Schneider, U.: Verhalten von Beton bei hohen Temperaturen. Heft 337 des DAfStB, Berlin 1982

12/ Kupfer,H.: Das Verhalten des Betons unter mehrachsiger Kurzzeitbelastung unter besonderer Berüksichtigung der $z$ weiachsigen Beanspruchung. Heft 229 des DAfStB, Berlin 1973

13/ Ehm,C.; Schneider, U.; Kordina,K.: Fracture of Concrete under Biaxial High Temperature Tests. Proceedings of the 6 th International Conference on Fracture, New Delhi 1984

14/ Hilsdorf,H.: Die Bestimmung der zweiachsigen Festigkeit des Betons. Heft 173 des DAfStb, Berlin 1965

15/ Ehm,C.; Kordina,K.; Schneider, U.: The Behaviour of Concrete under Biaxial Conditions and High Temperatures. RILEM International Conference on Concrete under Multiaxial Conditions, Toulouse 1984 